\title{
Effect of electroacupuncture at the ST36 and GB39 acupoints on apoptosis by regulating the p53 signaling pathway in adjuvant arthritis rats
}

\author{
CHENGGUO SU ${ }^{1 *}$, YUZHOU CHEN $^{1 *}$, YUNFEI CHEN $^{2}$, YIN ZHOU $^{2}$, LIANBO LI $^{2}$, \\ QUNWEN LU ${ }^{1}$, HUAHUI LIU ${ }^{1}$, XIAOCHAO LUO ${ }^{1}$ and JUN ZHU ${ }^{1}$
}

\author{
${ }^{1}$ Department of Acupuncture-Moxibustion and Tuina, The Third Affiliated Hospital of Chengdu University of \\ Traditional Chinese Medicine, Chengdu, Sichuan $611137 ;{ }^{2}$ Yueyang Hospital of Integrated Traditional Chinese and \\ Western Medicine, Shanghai University of Traditional Chinese Medicine, Shanghai 200437, P.R. China
}

Received April 1,2019; Accepted August 23, 2019

DOI: $10.3892 / \mathrm{mmr} .2019 .10674$

\begin{abstract}
MDM2) serve key regulatory roles in the apoptosis of synovial cells. The present study aimed to investigate the effects of electroacupuncture (EA) at the 'Zusanli' (ST36) and 'Xuanzhong' (GB39) acupoints on apoptosis in an adjuvant arthritis (AA) rat model. A total of 40 male Sprague-Dawley rats were randomly divided into Control, AA, AA + EA and $\mathrm{AA}+$ sham EA groups ( $\mathrm{n}=10$ rats in each group). Rats in all the groups, with the exception of the control group, were injected with Complete ${ }^{\mathrm{TM}}$ Freund's adjuvant into the bilateral hindlimb footpad to establish the AA model. Rats in the AA + EA group were treated with EA at the ST36 and GB39 acupoints. Rats in the AA + sham EA group were treated with percutaneous electrical stimulation at a position of $5 \mathrm{~mm}$ away from the ST36 and GB39 acupoints. The arthritis index scores and hindlimb paw volumes of the rats in each group were recorded. Subsequently, pathological changes in the synovial tissue were evaluated by hematoxylin and eosin (H\&E) staining, and the apoptotic rate of the synovial cells was detected by TUNEL staining. In addition, the expression levels of the apoptosis-associated proteins, Bax, phorbol-12-myristate-13-acetate-induced protein 1 (Noxa) and p53 upregulated modulator of apoptosis (PUMA), were determined by western blot analysis. The expression of both the gene and protein of $\mathrm{p} 53$ and MDM2 in synovial tissue was detected by reverse transcription-quantitative polymerase
\end{abstract}

Correspondence to: Dr Jun Zhu, Department of AcupunctureMoxibustion and Tuina, The Third Affiliated Hospital of Chengdu University of Traditional Chinese Medicine, 37 Shierqiao Road, Chengdu, Sichuan 611137, P.R. China

E-mail: zhujuntcm@163.com

*Contributed equally

Key words: electroacupuncture, adjuvant arthritis, synovial cells, apoptosis, p53 signaling pathway chain reaction (RT-qPCR) and western blot analysis, respectively. The results indicated that the arthritis index scores and hindlimb paw volumes upon EA stimulation were significantly decreased compared with those of the AA group $(\mathrm{P}<0.05)$. $\mathrm{H} \& \mathrm{E}$ staining revealed that the synovial inflammation of EA stimulation was significantly decreased compared with the AA group $(\mathrm{P}<0.05)$. The TUNEL assay results indicated that the apoptotic rate of synovial cells in the AA + EA group was significantly increased compared with that in the AA group $(\mathrm{P}<0.05)$. Furthermore, an increased expression of proapoptotic proteins was confirmed by the increased expression levels of Bax, Noxa and PUMA in the AA + EA group. The results of RT-qPCR and western blot analysis demonstrated that, compared with the AA group, EA stimulation led to a marked increase in p53 $(\mathrm{P}<0.05)$ and a significant decrease in MDM2 $(\mathrm{P}<0.05)$ gene and protein expression. Taken together, these results demonstrated that EA performed on the ST36 and GB39 acupoints led to a significant amelioration in AA injury of model rats, by regulating the p53 signaling pathway and inducing apoptosis.

\section{Introduction}

Rheumatoid arthritis (RA) is a clinically common, chronic, systemic autoimmune disease characterized by 'tumor-like' abnormal excessive proliferation of joint synovial cells, inflammatory cell infiltration, pannus formation, and cartilage and bone destruction (1-4). However, the precise mechanisms associated with the pathogenesis of RA have yet to be fully elucidated. With the deepening of research on the pathogenesis of RA, it has been revealed that an imbalance between cell proliferation of the joint synovial membrane and apoptosis is closely associated with the progression of RA (5-8). The tumor suppressor gene, p53, exerts a crucial role in the induction of cell apoptosis, and serves as the transcription factor for some anti- and pro-apoptotic proteins; namely, Bax, phorbol-12-myristate-13-acetate-induced protein 1 (Noxa), p53 upregulated modulator of apoptosis (PUMA) and mouse double minute 2 homolog (MDM2) (9-14). MDM2 is an important negative regulator of $\mathrm{p} 53$, which, upon combining 
with p53, inhibits apoptosis and stimulates cellular inflammation via forming a negative feedback regulatory loop, therefore functioning in a p53-dependent capacity $(15,16)$. Bax, Noxa, and PUMA are pro-apoptotic proteins belonging to the B-cell lymphoma-2 (Bcl-2) protein family, and are closely associated with mitochondrial-dependent apoptosis, serving as major effectors of p53-mediated cell death (17-19). A previously published study suggested that the upregulated p53 gene in chondrocytes of patients with RA was closely associated with the apoptosis of RA cells (20). Overexpression of the p53 gene in the early stages of disease led to an increase in synovial fibroblast apoptosis, thereby alleviating progression of the disease in an adjuvant arthritis (AA) rat model (21). The expression of MDM2 in fibroblasts of patients with RA was significantly increased and positively correlated with the disease activity of RA, and inhibition of MDM2 effectively inhibited the inflammatory response of RA (16). Upregulation of Bax, Noxa and PUMA has been observed in the apoptosis model of RA fibroblast-like synoviocytes (22-26).

Clinical studies have confirmed that acupuncture has the potential to be an effective therapy for patients with RA via inhibiting the inflammatory reaction and autoimmunity (27-29). Animal experimental studies have also confirmed that electroacupuncture (EA) intervention may lead to a significant inhibition of infiltration of local inflammatory cells, a decrease in the expression of inflammatory cytokines, and the proliferation of synovial cells, thereby effectively hindering disease progression in an RA rat model (28,30-32). An additional previously published study disclosed that the regulation of apoptosis was involved in the protective effects of acupuncture (33). It has been demonstrated that acupuncture intervention is able to improve memory and cognitive function by means of inhibiting neuronal apoptosis via increases in the expression of p53 protein in the cerebral cortex of Alzheimer's disease model mice (34). However, knockout of the p53 gene in the midbrain dopamine neurons of Alzheimer's disease model mice was able to eliminate the protective effect of acupuncture (35). Furthermore, previous evidence has also suggested that EA protects rats from ischemic brain injury by inhibiting the protein level of MDM2 (36). EA stimulation was also able to inhibit cerebral ischemia (CI) injury-induced cell apoptosis of cerebral and myocardial tissues in CI rats, which was discussed as being potentially associated with the downregulation of Bax expression, and upregulation of $\mathrm{Bcl}-2$ expression, in both myocardial and cerebral tissues (37). Furthermore, it has been revealed that EA improves learning and memory ability, and protects pyramidal cells from apoptosis, by blocking expression of p53 and Noxa in the hippocampal CA1 region of vascular dementia (VD) rats. Increasing expression levels of p53 and Noxa, therefore, have important roles in the pathogenesis of VD (38). Considered collectively, these results suggest that acupuncture may be able to treat certain diseases by regulating p53, Bax, Noxa, and MDM2. However, to the best of our knowledge, whether EA is able to suppress proliferation by regulating the p53 signaling pathway has not been previously investigated. In the present study, an AA rat model was established, and the molecular mechanism was investigated via the simultaneous EA of the acupoints 'Zusanli' (ST36) and 'Xuanzhong' (GB39).

\section{Materials and methods}

Animals and experimental design. The present study was approved by the Scientific Investigation Board of the Chengdu University of Traditional Chinese Medicine. All animal experiments followed the National Institutes of Health Guide for the Care and Use of Laboratory Animals (39). A total of 40 7-week-old male Sprague-Dawley rats (weight, 170-180 g) were provided by Chengdu Dashuo Laboratory Animal Co., Ltd and housed under standard conditions of temperature and humidity (12: $12 \mathrm{~h}$ light: Dark cycle; indoor temperature, $23 \pm 3^{\circ} \mathrm{C}$; humidity, $60 \pm 10 \%$ ). In addition, rats had ad libitum access to standard rodent chow and water. After a 7 day period of acclimation, rats were randomly divided into four groups, with 10 rats/group: Control; AA; AA + EA; and AA + sham EA.

Experimental induction of $A A$ in rats and EA treatment. With the exception of the control rats, all rats received an intradermal injection of $0.1 \mathrm{ml} \mathrm{Complete}^{\mathrm{TM}}$ Freund's adjuvant (CFA; cat. no. F5881; Merck KGaA) into both hind paws to induce AA. An equivalent volume of saline was administered to each rat in the control group by intradermal injection. On day 3 following AA induction, EA stimulation was performed with sterile metallic needles (Beijing Tianyuheng Technology Co., Ltd.) with a width of $0.25 \mathrm{~mm}$ and a length of $25 \mathrm{~mm}$, which synchronously entered the ST36 (7 mm depth) and GB39 (3 mm depth) acupoints, as described previously (31). The pattern of stimulus frequency and duration was $2 \mathrm{~Hz}$ for $15 \mathrm{~min}$ using a commercial electric acupuncture apparatus (SDZ-II; Suzhou Medical Appliance Factory). EA treatment was administered every other day for 16 days. In the AA + sham EA group, similar EA procedures were performed; however, the needles were inserted into inappropriate acupoints (specifically, rats in the AA + sham EA group were treated with percutaneous electrical stimulation at a position of $5 \mathrm{~mm}$ away from the acupoints of ST36 and GB39).

Evaluation of development of arthritis. The arthritic index and foot swelling (i.e., measurement of the hindlimb paw volume) were measured on days $0,3,8,13$ and 18 following AA induction, as previously described $(30,40)$. In brief, the polyarthritis severity was graded on a scale of $0-4$, and scored as follows: 0 , no swelling; 1 , swelling of finger joints; 2 , mild swelling of ankle or wrist joints; 3 , severe inflammation of the entire paws; 4, paws with deformity or ankylosis. The foot swelling was determined by a volume drainage method using a plethysmograph apparatus (YLS-7A; Yiyan Sci, Ltd.).

Histopathological analysis. The rats were sacrificed on day 18 following AA induction by intraperitoneal injection with $200 \mathrm{mg} / \mathrm{kg}$ sodium pentobarbital. Following previous studies of histological analysis $(41,42)$, the ankle joints were harvested and fixed in $4 \%$ paraformaldehyde for $48 \mathrm{~h}$ at $4{ }^{\circ} \mathrm{C}$, and then were subsequently decalcified using a commercial tissue decalcification reagent according to the manufacturer's protocol (cat. no. G1107; Wuhan Servicebio Technology Co., Ltd.) and embedded in paraffin. The tissues were then sliced into $4-\mu \mathrm{m}$ thick sections. Following washing with xylene I and II for 20 min and dehydration with 100,95,80 and 70\% ethanol for $5 \mathrm{~min}$ each, the sections were stained with hematoxylin 
for $30 \mathrm{~min}$ at $25^{\circ} \mathrm{C}$, washed with water for $20 \mathrm{~min}$, stained with eosin for $5 \mathrm{~min}$ at $25^{\circ} \mathrm{C}$. Finally, images of the sections were captured under a light microscope (BX53; Olympus Corporation) at magnification, $x 400$. The stained sections were scored blindly by 2 investigators, as described previously (30).

Terminal deoxynucleotidyl-transferase-mediated dUTP nick end labeling (TUNEL) staining. The effect of EA on apoptosis was determined using a TUNEL assay, according to the manufacturer's protocol (cat. no. ab15251; Roche Diagnostics). Briefly, following fixation in $4 \%$ paraformaldehyde for $48 \mathrm{~h}$ at $4^{\circ} \mathrm{C}$, and after deparaffinization and dehydration, the ankle joint sections were treated with proteinase $\mathrm{K}(20 \mu \mathrm{g} / \mathrm{ml})$ for $15 \mathrm{~min}$ at room temperature. Subsequently, equilibration buffer was applied for $10 \mathrm{sec}$, and the specimens were immersed and incubated for $1 \mathrm{~h}$ in working strength terminal deoxynucleotidyl transferase (TdT) enzyme solution at $37^{\circ} \mathrm{C}$. Following incubation in stop/wash buffer for $10 \mathrm{~min}$ to terminate the reaction, sections were incubated for $30 \mathrm{~min}$ in working strength anti-digoxigenin conjugate at room temperature in the dark to visualize the DNA fragments. Proteinase K, equilibration buffer, and stop/wash buffer were all included in the TUNEL assay kit. Finally, the slides were counterstained with $0.5 \mu \mathrm{g} / \mathrm{ml}$ DAPI, and mounted in fluorescence mounting medium. Sections treated only with reaction buffer lacking the TdT enzyme were used as negative controls. To quantify the numbers of apoptotic cells, images of 6 randomly chosen high power fields/slide at magnification, $\mathrm{x} 200$, were captured by a blinded examiner using a wide-field fluorescence microscope (Olympus BX53; Olympus Corporation). TUNEL ${ }^{+}$nuclei were quantified by automatic counting using Image J software (v.1.47t; National Institutes of Health).

RNA isolation and reverse transcription-quantitative polymerase chain reaction $(R T-q P C R)$. Total RNA was extracted from synovial tissues using an RNA extraction kit (cat. no. G3013; Wuhan Servicebio Technology Co., Ltd). RNA was quantified using a NanoDrop ${ }^{\text {TM }} 2000$ spectrophotometer (NanoDrop Technologies; Thermo Fisher Scientific, Inc.), and then immediately reverse-transcribed into cDNA using a cDNA synthesis kit (cat. no. K1622; Thermo Fisher Scientific, Inc., Waltham, MA, USA), according to the manufacturer's protocols. Subsequently, qPCR was performed with SYBR $^{\circledR}$ Premix EX Taq ${ }^{\mathrm{TM}}$ II (Takara Biotechnology Co., Ltd.) on an ABI PRISM ${ }^{\circledR} 7900$ HT Sequence Detection system (Thermo Fisher Scientific, Inc.). The thermocycling protocol was as follows: Initial denaturation at $95^{\circ} \mathrm{C}$ for $10 \mathrm{~min}$, followed by 45 cycles of $15 \mathrm{sec}$ at $95^{\circ} \mathrm{C}$ (denaturation), $60 \mathrm{sec}$ at $60^{\circ} \mathrm{C}$ (primer annealing) and $15 \mathrm{sec}$ at $60^{\circ} \mathrm{C}$ (elongation), and a final extension step for $10 \mathrm{~min}$ at $72^{\circ} \mathrm{C}$. The primer sequences used for qPCR are presented in Table I. GAPDH was used as the internal reference, and relative gene expression levels were calculated using the $2^{-\Delta \Delta \mathrm{Cq}}$ method (43).

Western blot analysis. As described previously (44), frozen rat ankle synovial tissues were homogenized in cold whole cell lysis buffer (cat. no. G2002; Wuhan Servicebio Technology Co., Ltd.) and subsequently centrifuged at 14,000 x g for $5 \mathrm{~min}$ at $4^{\circ} \mathrm{C}$. Protein concentration in the supernatant
Table I. Primers used for reverse transcription-quantitative polymerase chain reaction in the present study.

\begin{tabular}{ll}
\hline Gene & \multicolumn{1}{c}{ Primer sequences (5'-3') } \\
\hline GAPDH & F: CTGGAGAAACCTGCCAAGTATG \\
& R: GGTGGAAGAATGGGAGTTGCT \\
p53 & F: GGAATCTTCTGGGACGGGA \\
& R: CCACGGATCTTAAGGGTGAAAT \\
MDM2 & F: AGGCAGAAGAAGGCTTAGATGTG \\
& R: CGGCTGGGAATAGTCGTCAC
\end{tabular}

MDM2, mouse double minute 2 homolog. F, forward; R, reverse.

was standardized using a protein concentration assay kit (cat. no. G2026; Wuhan Servicebio Technology Co., Ltd.). A total of $40 \mu \mathrm{g}$ protein per lane was separated using $10 \%$ SDS-PAGE gels, and subsequently transferred onto polyvinylidene difluoride membranes. The membranes were blocked with $5 \%$ bovine serum albumin (cat. no. G2013; Wuhan Servicebio Technology Co., Ltd.) for $2 \mathrm{~h}$ at $25^{\circ} \mathrm{C}$, followed by incubation with primary antibodies against p53 (dilution, 1:1,000; cat. no. ab131442; Abcam), MDM2 (1:1,000; cat. no. ab38618; Abcam), PUMA (1:1,000; cat. no,. bs-1573R; BIOSS), Bax (1:500; cat. no. bs-0127M; BIOSS), NOXA $(1: 1,000$; cat. no. bs-19322R; BIOSS), $\beta$-actin $(1: 3,000$; cat. no. GB12001; Wuhan Servicebio Technology Co., Ltd.), and GAPDH [1:1,000; cat. no. 70-ab011-100; MultiSciences (Lianke) Biotech Co., Ltd.] overnight at $4^{\circ} \mathrm{C}$. The following day, membranes were incubated with horseradish peroxidase-conjugated goat anti-rabbit immunoglobulin $\mathrm{G}$ secondary antibodies (1:5,000; cat. no. 70-GAR007; MultiSciences) for $2 \mathrm{~h}$ at $25^{\circ} \mathrm{C}$. Finally, protein bands were developed using a Chemidoc $^{\mathrm{TM}}$ XRS Imaging system (Bio-Rad Laboratories, Inc.). The bands of interest were quantified, and normalized against GAPDH using Image-Pro Plus v.6.0 software (Media Cybernetics, Inc.).

Statistical analysis. The data are presented as the mean \pm standard deviation. Differences between groups were analyzed using one-way analysis of variance, followed by Tukey multiple comparison post-hoc tests. Statistical analyses were performed with SPSS 19.0 software (IBM Corp.). $\mathrm{P}<0.05$ was considered to indicate a statistically significant difference.

\section{Results}

EA stimulation decreases the arthritis index scores of $A A$ rats. As presented in Fig. 1, the arthritis index scores in the $\mathrm{AA}, \mathrm{AA}+\mathrm{EA}$ and AA + sham EA groups were significantly increased on day 3 following AA induction $(\mathrm{P}<0.01)$, indicating that the AA model had been successfully established. During the course of the experiment, the arthritis index score in the AA group increased gradually. EA intervention significantly decreased the arthritis index score $(\mathrm{P}<0.01)$. However, no significant differences were identified between the AA + sham EA and AA groups ( $\mathrm{P}>0.05)$. 


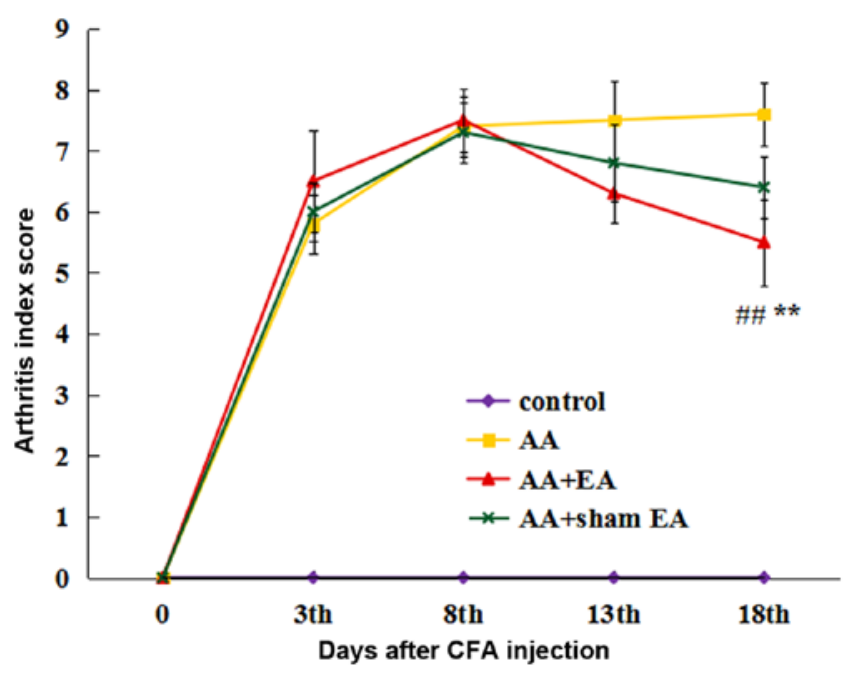

Figure 1. Effect of EA on the arthritic index in rats with AA. Data are expressed as the mean \pm standard deviation $(n=10) .{ }^{* *} \mathrm{P}<0.01$ vs. the control group; ${ }^{\#} \mathrm{P}<0.01$ vs. the AA group. EA, electroacupuncture; AA, adjuvant arthritis.

EA stimulation inhibits foot swelling in AA rats. The foot swelling was measured by the volume drainage method (Fig. 2). Prior to initiation of the experiment, no significant differences in the size of foot swelling were observed between the groups. At 3 days after the injection of CFA, a significant increase in foot volume was observed in all groups, with the exception of the control group. After 8 sessions of EA stimulation, foot swelling in the AA + EA group was markedly alleviated compared with that in the AA group $(\mathrm{P}<0.01)$; by contrast, foot swelling in the $\mathrm{AA}+$ sham EA group was not decreased compared with that in the AA group $(\mathrm{P}>0.05)$.

EA stimulation improves the pathological morphology of synovial tissue in AA rats. Histological analysis revealed that the inner-surface-layer synovial cells in the ankle joint of the control group were smooth and flat, and the cells were neatly arranged without any indications of inflammatory cell infiltration or synovial cell proliferation (Fig. 3). By contrast, the synovial tissue of the ankle joint was highly proliferated, with irregular cell arrangement, significant infiltration of inflammatory cells, increased new capillary development, pannus formation, and synovitis in the AA group. However, in the $\mathrm{AA}+\mathrm{EA}$ group, the results of H\&E staining appeared to be similar to those of the control group.

EA stimulation increases the apoptotic rate of synovial cells in AA rats. Subsequently, cell death was observed using a TUNEL assay. Compared with the control group, the percentage of TUNEL-positive cells increased markedly in the AA group $(\mathrm{P}<0.01$; Fig. 4A). However, compared with the AA + sham EA and AA groups, EA stimulation led to a further, marked increase in the number of TUNEL-positive cells $(\mathrm{P}<0.01)$. Additionally, no significant difference in the apoptotic cell ratio was observed between the AA + sham EA and AA groups $(\mathrm{P}>0.05)$.

Subsequently, expression levels of the pro-apoptosisassociated proteins, Bax, Noxa and PUMA, were detected by

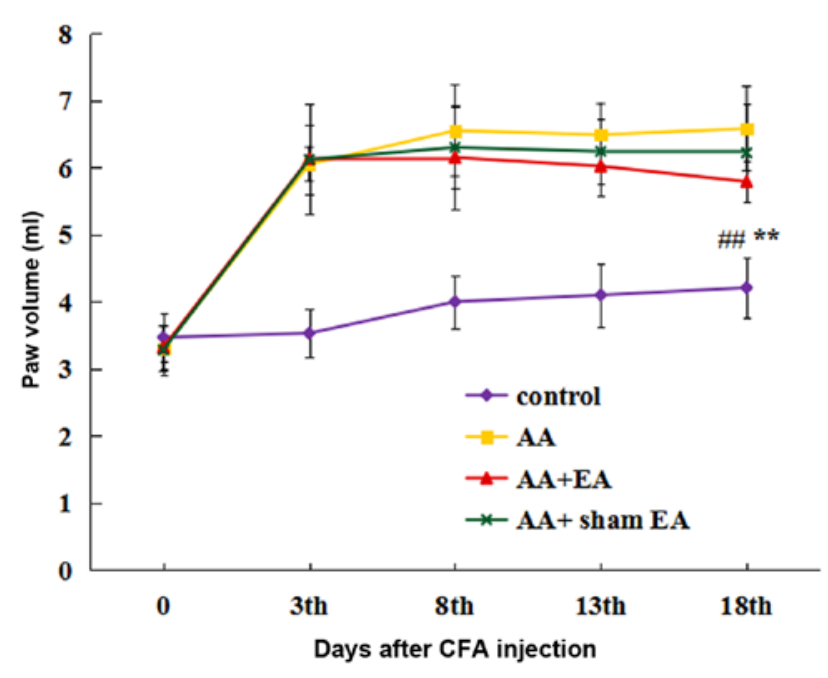

Figure 2. Effect of EA on foot swelling in rats with AA. Data are expressed as the mean \pm standard deviation $(n=10) .{ }^{* *} \mathrm{P}<0.01$ vs. the control group; ${ }^{\# \#} \mathrm{P}<0.01$ vs. the AA group. EA, electroacupuncture; AA, adjuvant arthritis.

western blot analysis. As demonstrated in Fig. 4B, treatment of rats with AA resulted in increased Bax, Noxa and PUMA protein levels compared with the control group $(\mathrm{P}<0.01)$. EA stimulation caused an additional increase in Bax, Noxa and PUMA protein expression $(\mathrm{P}<0.01)$. However, compared with the AA group, sham acupuncture stimulation elicited no effect on Bax, Noxa and PUMA protein expression $(\mathrm{P}>0.05)$.

EA stimulation regulates the expression of 553 and MDM2 in synovial tissue of AA rats. As demonstrated in Fig. 5A-C, increased levels of p53 and MDM2 protein in synovial tissue were observed in the AA group compared with the control group $(\mathrm{P}<0.01)$. Additionally, EA stimulation resulted in an additional increase in $\mathrm{p} 53$ protein expression $(\mathrm{P}<0.01)$. However, by contrast, EA stimulation inhibited MDM2 protein expression $(\mathrm{P}<0.01)$. Consistently, sham acupuncture stimulation exerted no effect on p53 and MDM2 protein expression compared with the AA group ( $\mathrm{P}>0.05)$. In addition, treatment of rats with AA led to significantly increased gene expression levels of the p53 and MDM2 genes (Fig. 5D and E) compared with the control group $(\mathrm{P}<0.01)$. However, increased and decreased expression mRNA levels of p53 and MDM2, respectively, were detected following EA stimulation $(\mathrm{P}<0.01)$. Compared with the AA group, sham acupuncture stimulation produced no effect on p53 and MDM2 gene expression $(\mathrm{P}>0.05)$.

\section{Discussion}

Neovascularization and synovial cell proliferation are two key factors in the progression of RA. Our recently published article focused on the inhibitory effect of electroacupuncture (EA) on synovial neovascularization in RA rats. The results of this study suggested that EA intervention may inhibit neovascularization by downregulating the expression of HIF-1 $\alpha$ and VEGF (45). The present study aimed to investigate the effect of EA on the abnormal proliferation of synovial cells in RA rats. The present study has demonstrated that EA is able to effectively inhibit arthritis in AA rats, promote synovial 


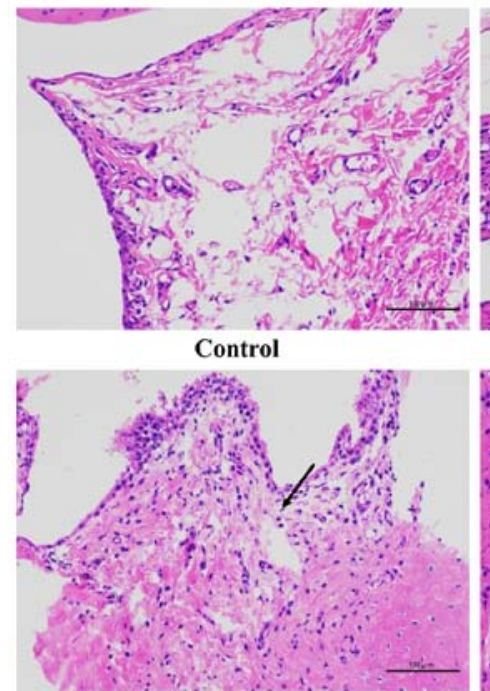

$\mathbf{A A}+\mathbf{E A}$

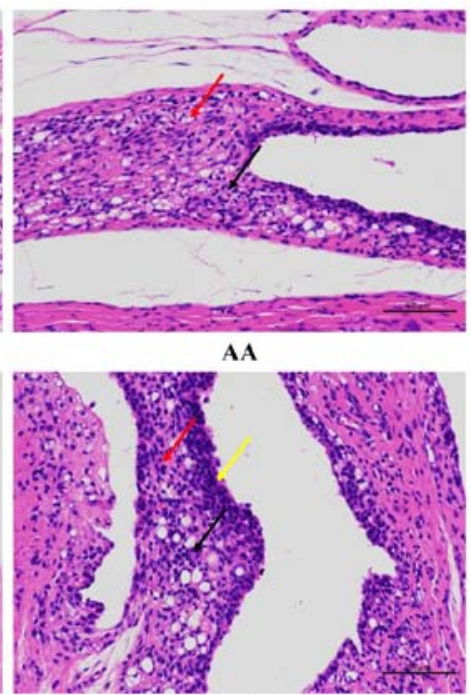

AA+sham EA

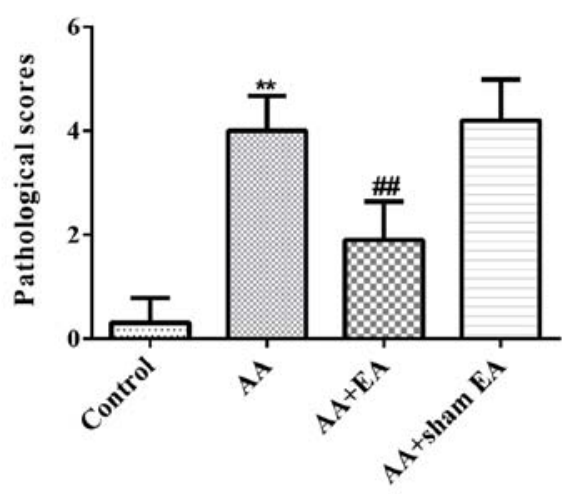

Figure 3. Effects of EA on ankle joint damage in AA rats. Representative microphotographs of ankle joint sections from various groups (H\&E stain, magnification, $\mathrm{x} 400)$. Data are expressed as the mean \pm standard deviation $(\mathrm{n}=10)$. ${ }^{* *} \mathrm{P}<0.01$ vs. the control group; ${ }^{\#} \mathrm{P}<0.01 \mathrm{vs}$. the AA group. The red arrows indicate hyperplastic synoviocytes, the black arrows indicate infiltrating inflammatory cells, and the yellow arrows indicate hyperplastic synovial lining cells. EA, electroacupuncture; AA, adjuvant arthritis; H\&E, hematoxylin and eosin.

cell apoptosis, increase the expression levels of p53 and its downstream factors, and decrease the expression of MDM2, a negative regulator of p53 (Fig. 6).

Synovial cell proliferation is a hallmark pathology of RA, which is largely due to the abnormal proliferation and insufficient apoptosis of fibroblast-like synoviocytes of RA, which exhibit 'tumor-cell-like' properties, including unlimited proliferation, resistance to cell death, and aggressive invasion and migration $(3,7,46,47)$. Previous studies have suggested that the abnormal apoptosis of synovial cells is associated with RA, and decreased levels of apoptosis may lead to excessive proliferation of synovial tissue, thus promoting the deterioration of RA $(5,6,48)$. Previous studies have demonstrated that inducing apoptosis of synovial cells effectively leads to an inhibition of cellular proliferation $(49,50)$. An additional study revealed that acupuncture therapy may be involved in the regulation of apoptosis, and that the underlying mechanism is predominantly governed by regulating apoptosis-associated genes, cytokines and other intracellular small molecules, including p53, MDM2, Bax, Noxa and PUMA (51).

One previous study identified that fibroblast-like synoviocytes (FLS) obtained from AA rats significantly proliferated and exhibited increased levels of pro-inflammatory cytokines TNF- $\alpha$ and IL- $\beta$ compared with the control group. Concomitantly, the apoptotic rate of FLS was significantly decreased, the expression level of anti-apoptotic protein Bcl-2 was upregulated, and the relative expression of Bax was decreased. A potential mechanism is that the mitochondrial apoptotic pathway of AA-FLS is inhibited and exhibits anti-apoptotic properties, while arthritic symptoms are manifested (52). A second study indicated that increasing the apoptotic rate of synovial cells in AA rats may significantly improve the symptoms of arthritis. Its mechanism may be associated with decreases in Bcl-2 and increases in Bax expression levels, and increases in caspase-3 activity (53).
In the present study, AA rats were selected as a model of RA, which is the most commonly used animal model $(54,55)$. The results indicated that, compared with the control group, after $72 \mathrm{~h}$, the toes and ankles of RA rats possessed different degrees of swelling, deformity and increased arthritis index scores. The results of the H\&E staining of synovial tissue revealed abnormal proliferation of synovial cells, connective tissue and blood capillaries. Furthermore, a large number of inflammatory cells had infiltrated the synovium. Concomitantly, the proportion of TUNEL-positive cells increased markedly in the AA group. These pathological changes in the AA rat model were consistent both with the symptoms of patients with clinical RA and with pathological lesions in previously described experimental animal models $(32,56)$.

Previous studies have suggested that $\mathrm{p} 53$, a tumor suppressor factor, fulfills a crucial role in mitochondrial-dependent apoptosis $(12,13)$. MDM2 is a key negative regulator of $\mathrm{p} 53$, affecting the transcriptional activity and stability of p53, and thereby forms a negative feedback pathway with p53 $(15,16)$. Previous studies have indicated that in wild-type cells, p53 expression is maintained at a very low level under normal physiological conditions. However, in the state of cellular stress including hypoxia and DNA damage, p53 is stabilized and accumulated. In addition, enhanced transcriptional activity of p53 may increase the expression of MDM2, a downstream regulator of p53 (57-59). In accordance with previous studies $(31,60)$, in the present study, EA performed on the ST36 and GB39 acupoints resulted in an inhibition of the proliferation of synovial cells and joint inflammation in rats. Notably, the results of the present study also indicated that EA stimulation led to a marked increase in synovial cell apoptosis, as evidenced by intensive TUNEL-positive staining. Furthermore, compared with the AA group, the protein and gene expression levels of p53 were demonstrated to increase in the synovial cells of AA rats, whereas the protein and gene expression levels of MDM2 were inhibited. 

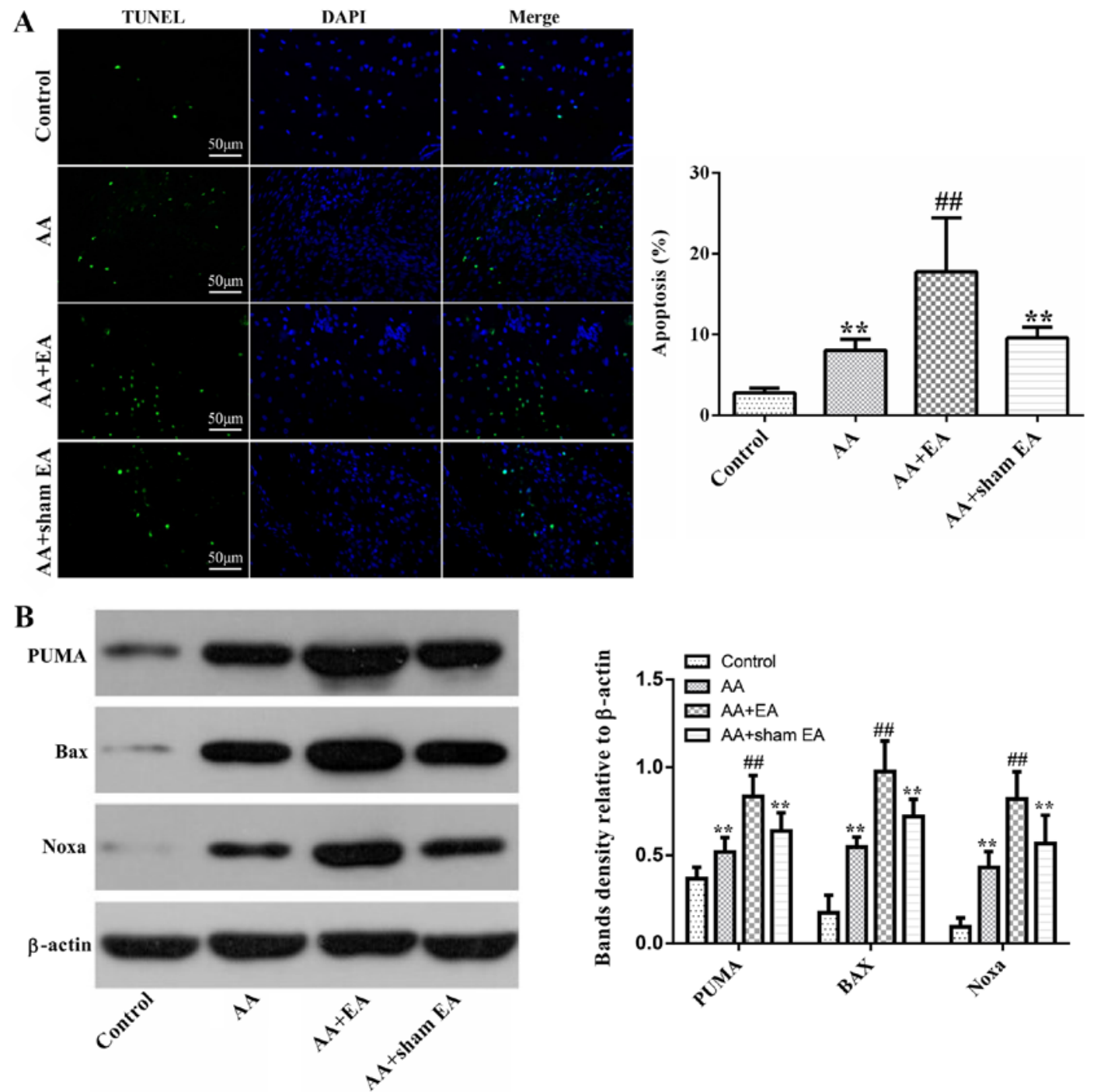

Figure 4. Effects of EA on synovial cell apoptosis. (A) Terminal deoxynucleotidyl-transferase-mediated dUTP nick end labeling staining of apoptotic cells in AA rats. (B) Expression of the proapoptotic proteins, Bax, Noxa and PUMA. Data are expressed as the mean \pm standard deviation ( $\mathrm{n}=10) .{ }^{* *} \mathrm{P}<0.01 \mathrm{vs}$. the control group; ${ }^{\# \#} \mathrm{P}<0.01$ vs. the AA group. EA, electroacupuncture; AA, adjuvant arthritis; Noxa, phorbol-12-myristate-13-acetate-induced protein 1; PUMA, p53 upregulated modulator of apoptosis.

Previous data have suggested that increased levels of p53-induced apoptosis occur in fibroblasts of AA rat synovial tissue during increasing and chronic arthritis (16,21,31,61-65). Additionally, inhibited expression of the p53 gene in synovial fibroblasts may lead to upregulation of inflammatory factors in $\mathrm{CD}^{+}{ }^{+} \mathrm{T}$ lymphocytes of patients with RA, including interleukin-17 and interferon- $\gamma(66)$. Taken together, an accumulation of the p53 gene product may alleviate RA via inhibiting the inflammatory factor-induced subsequent spread of inflammatory reactions, and inducing apoptosis in synovial tissue. Zhang et al (16) demonstrated that the expression of MDM2 protein was significantly increased in fibroblast-like synovial cells of patients with RA, and that this was positively correlated with the disease activity of RA. In addition, inhibition of MDM2 protein expression may serve an anti-inflammatory role by regulating the mitogen-activated protein kinase and NF- $\mathrm{\kappa B}$ signaling pathways in collagen-induced arthritic mice (67).

Previous studies have indicated that local hypoxia of synovial joints caused by RA may activate the p53-mediated mitochondrial apoptotic pathway $(18,19)$. It has been suggested that, as a downstream effector of the Bcl-2 protein family, p53 fulfills a crucial role in mitochondrial-dependent apoptosis, a process that results in abnormal expression of Bax, Noxa and PUMA (12-14). Noxa may inhibit the expression of anti-apoptotic Bcl-2 family members, while PUMA increases the expression and conformational changes of Bax, which in turn contributes to pore formation $(13,17,68-70)$. The results of the present study indicated that compared with the AA group, EA intervention may increase the expression of Bax, Noxa and PUMA proteins in the downstream regulatory genes of $\mathrm{p} 53$.

The aforementioned results of the present study suggested that EA was able to effectively treat RA disease by regulating the expression of $\mathrm{p} 53$ and MDM2, and promoting further expression of the proapoptotic proteins, Bax, Noxa and PUMA, data that were consistent with previous studies $(16,20,21)$.

Prior clinical studies have suggested that the effects of acupuncture or EA intervention at acupoints are markedly improved compared with those of sham acupuncture intervention at non-acupoints near to acupoints (71-73). In an animal experiment on the anti-inflammatory effects of EA, pretreatment 
$\mathbf{A}$
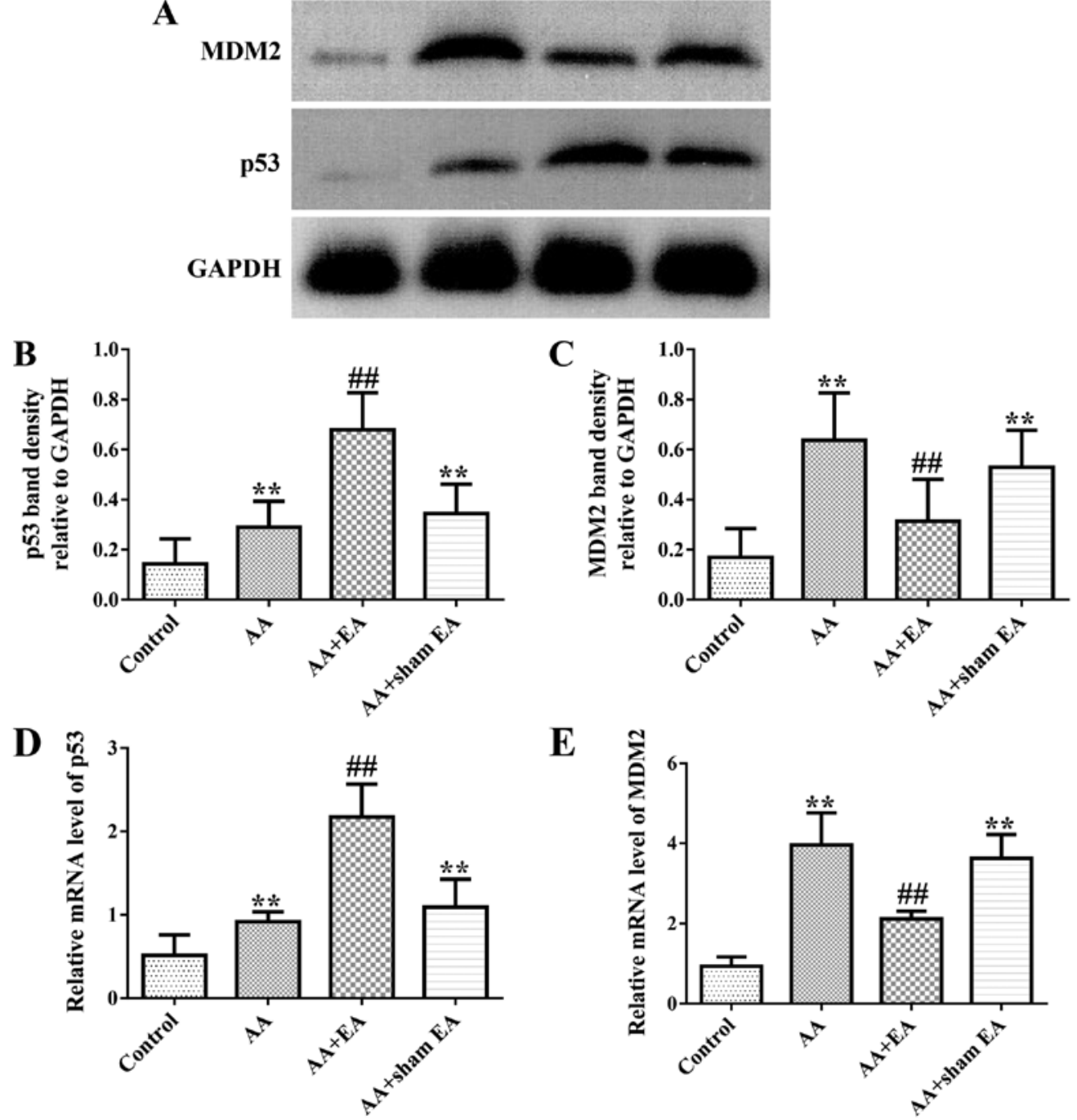

Figure 5. Effects of EA on the gene and protein expression of p53 and MDM2 in synovial tissues of the AA rats. (A) Typical examples of p53 and MDM2 protein expressions in synovial tissues from various groups. (B and C) Semi-quantitative statistical analysis of the relative p53 and MDM2 protein values. (D and E) Semi-quantitative statistical analysis of the p53 and MDM2 mRNA levels. Data are expressed as the mean \pm standard deviation ( $\mathrm{n}=10$ ). ${ }^{* *} \mathrm{P}<0.01 \mathrm{vs}$ the control group; ${ }^{\# \#} \mathrm{P}<0.01$ vs. the AA group. EA, electroacupuncture; AA, adjuvant arthritis; MDM2, mouse double minute 2 homolog.

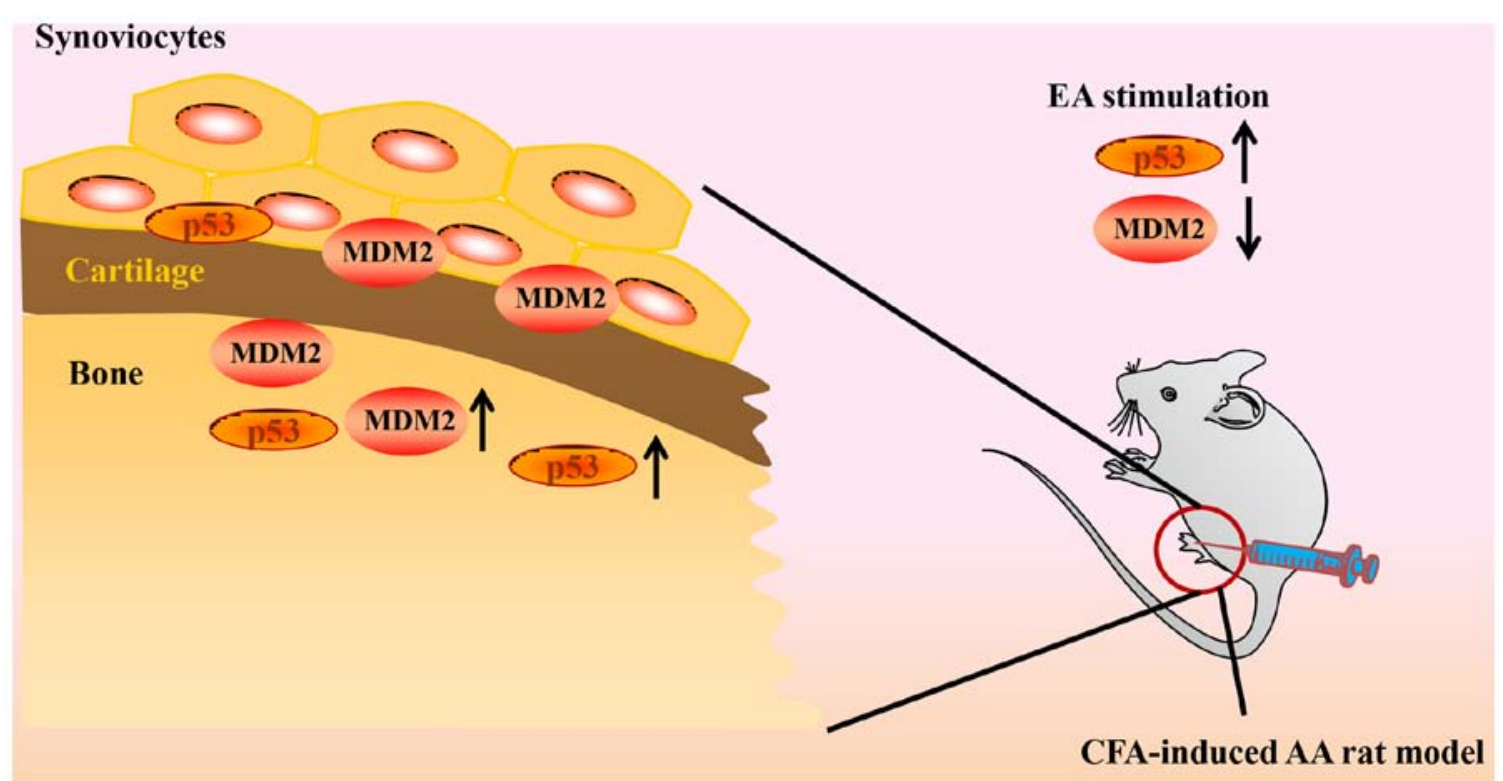

Figure 6. Proposed model demonstrating how EA alleviates AA rats. EA, electroacupuncture; AA, adjuvant arthritis; MDM2, mouse double minute 2 homolog; CFA, Complete ${ }^{\mathrm{TM}}$ Freund's adjuvant. 
of the Hegu acupoint led to an improvement in the survival rate of rats with lethal endotoxemia, whereas acupuncture at non-acupoints, located on the ulna side of the metacarpus, failed to elicit a similar effect (74). These results also suggested that the anti-inflammatory effects of EA on acupoints is markedly improved compared with that of non-acupoints. The results of the present study also confirmed that sham EA stimulation exerted no effect on the arthritis scores, pathological lesions of synovial joints, apoptosis, or gene or protein expression of $\mathrm{p} 53$ and its downstream factors including Bax, Noxa, PUMA, or MDM2, compared with the AA group; these data were consistent with previous studies $(6,21,26)$.

In conclusion, the results from the present study have demonstrated that EA stimulation of the ST36 and GB39 acupoints exhibited potential therapeutic effects on AA rats. Furthermore, the underlying mechanisms may be associated with increases in the expression of the p53 signaling pathway, thereby inducing apoptosis in synovial tissue. However, further investigations are required to determine the precise mechanisms underlying activation of the p53 signaling pathway by EA.

\section{Acknowledgements}

Not applicable.

\section{Funding}

The current study was supported by the National Natural Science Foundation of China (grant nos. 81704152 and $81503599)$ and the project of the Science and Technology Department in Sichuan province (grant no. 2019YJ0491).

\section{Availability of data and materials}

The datasets used and/or analyzed during the present study are available from the corresponding author on reasonable request.

\section{Authors' contributions}

JZ designed and performed the experiments, and evaluated the data and reviewed the manuscript. CS performed the experiments and wrote the manuscript. YuzC, QL, HL and XL also performed the experiments. YZ, YunC and LL analyzed the data. All authors read and approved the final manuscript.

\section{Ethics approval and consent to participate}

The present study was approved by the Scientific Investigation Board of the Chengdu University of Traditional Chinese Medicine. All animal experiments followed the National Institutes of Health Guide for the Care and Use of Laboratory Animals.

\section{Patient consent for publication}

Not applicable.

\section{Competing interests}

The authors declare that they have no competing interests.

\section{References}

1. Firestein GS: Evolving concepts of rheumatoid arthritis. Nature 423: 356-361, 2003.

2. Matsui T, Nakata N, Nagai S, Nakatani A, Takahashi M, Momose T, Ohtomo K and Koyasu S: Inflammatory cytokines and hypoxia contribute to 18F-FDG uptake by cells involved in pannus formation in rheumatoid arthritis. J Nucl Med 50: 920-926, 2009.

3. Bartok B and Firestein GS: Fibroblast-like synoviocytes: Key effector cells in rheumatoid arthritis. Immunol Rev 233: 233-255, 2010.

4. Ma J, Wang X, Lv T, Liu J, Ren Y, Zhang J and Zhang Y: Effects of fhrelin on the apoptosis of rheumatoid arthritis fibroblast-like synoviocyte MH7A cells. Biol Pharm Bull 42: 158-163, 2019.

5. Mahoney JA and Rosen A: Apoptosis and autoimmunity. Curr Opin Immunol 17: 583-588, 2005.

6. Chou CT, Yang JS and Lee MR: Apoptosis in rheumatoid arthritis-expression of Fas, Fas-L, p53, and Bcl-2 in rheumatoid synovial tissues. J Pathol 193: 110-116, 2001.

7. Hou YN and Guo LH: Role of synovial fibroblasts in the pathogenesis of rheumatoid arthritis. Chin J Cell Biol 31: 157e162, 2009.

8. Li R, Cai L, Tang WJ, Lei C, Hu CM and Yu F: Apoptotic effect of geniposide on fibroblast-like synoviocytes in rats with adjuvant-induced arthritis via inhibiting ERK signal pathway in vitro. Inflflammation 39: 30-38, 2016

9. Aupperle KR, Boyle DL, Hendrix M, Seftor EA, Zvaifler NJ, Barbosa M and Firestein GS: Regulation of synoviocyte proliferation, apoptosis, and invasion by the p53 tumor suppressor gene. Am J Pathol 152: 1091-1098, 1998.

10. Tak PP, Zvaifler NJ, Green DR and Firestein GS: Rheumatoid arthritis and p53: How oxidative stress, might alter the course of inflammatory diseases. Immunol Today 21: 78-82, 2000.

11. Yamanishi Y, Boyle DL, Rosengren S, Green DR, Zvaifler NJ and Firestein GS: Regional analysis of p53 mutations in rheumatoid arthritis synovium. Proc Natl Acad Sci USA 99: 10025-10030, 2002.

12. Doroshevskaya AY, Kondratovskii PM, Dubikov AI and Eliseikina MG: Apoptosis regulator proteins: Basis for the development of innovation strategies for the treatment of rheumatoid arthritis in patients of different age. Bull Exp Biol Med 156: 377-380, 2014.

13. Nakano K and Vousden KH: PUMA, a novel proapoptotic gene, is induced by p53. Mol Cell 7: 683-694, 2001.

14. Villunger A, Michalak EM, Coultas L, Müllauer F, Böck G, Ausserlechner MJ, Adams JM and Strasser A: p53- and drug-induced apoptotic responses mediated by BH3-only proteins puma and Noxa. Science 302: 1036-1038, 2003.

15. Thomasova D, Mulay SR, Bruns H and Anders HJ: p53-Independent roles of MDM2 in NF- $\kappa$ B signaling: Implications for cancer therapy, wound healing, and autoimmune diseases. Neoplasia 14: 1097-1101, 2012.

16. Zhang L, Luo J, Wen H, Zhang T, Zuo X and Li X: MDM2 promotes rheumatoid arthritis via activation of MAPK and NF-kB. Int Immunopharmacol 30: 69-73, 2016.

17. Cory S and Adams JM: The Bcl2 family: Regulators of the cellular life-or-death switch. Nat Rev Cancer 2: 647-656, 2002.

18. Bouvard V, Zaitchouk T, Vacher M, Duthu A, Canivet M, Choisy-Rossi C, Nieruchalski $M$ and May E: Tissue and cell-specific expression of the p53-target genes: Bax, Fas, MDM2 and Waf1/p21, before and following ionising irradiation in mice. Oncogene 19: 649-660, 2000.

19. Ohtsuka T, Ryu H, Minamishima YA, Macip S, Sagara J, Nakayama KI, Aaronson SA and Lee SW: ASC is a Bax adaptor and regulates the p53-Bax mitochondrial apoptosis pathway. Nat Cell Biol 6: 121-128, 2004.

20. Itoh K, Hase H, Kojima H, Saotome K, Nishioka K and Kobata T: Central role of mitochondria and p53 in Fas-mediated apoptosis of rheumatoid synovial fibroblasts. Rheumatology (Oxford) 43: 277-285, 2004.

21. Tak PP, Klapwijk MS, Broersen SF, van de Geest DA, Overbeek M and Firestein GS: Apoptosis and 53 expression in rat adjuvant arthritis. Arthritis Res 2: 229-235, 2000.

22. Li Y, He N, Shen L and Liu M: Apoptotic effect of Aralia echinocaulis extract on fibroblast-like synoviocytes in rats with adjuvant-induced arthritis via inhibiting the Akt/Hif-1 $\alpha$ signaling pathway in vitro. J Pharmacol Sci 139: 340-345, 2019.

23. Cha HS, Rosengren S, Boyle DL and Firestein GS: PUMA regulation and proapoptotic effects in fibroblast-like synoviocytes. Arthritis Rheum 54: 587-592, 2006. 
24. Mazumder S, Choudhary GS, Al-Harbi S and Almasan A Mcl-1 phosphorylation defines ABT-737 resistance that can be overcome by increased NOXA expression in leukemic B cells. Cancer Res 72: 3069-3079, 2012.

25. Idrus E, Nakashima T, Wang L, Hayashi M, Okamoto K, Kodama T, Tanaka N, Taniguchi $\mathrm{T}$ and Takayanagi $\mathrm{H}$ : The role of the $\mathrm{BH} 3$-only protein Noxa in bone homeostasis. Biochem Biophys Res Commun 410: 620-625, 2011.

26. Cottier KE, Fogle EM, Fox DA and Ahmed S: Noxa in rheumatic diseases: Present understanding and future impact. Rheumatology (Oxford) 53: 1539-1546, 2014.

27. He G, Wu Z, Wang Q, et al: Therapeutic observation of electroacupuncture plus electromagnetic therapy for rheumatoid arthritis. Shanghai J Acupuncture Moxibustion 33: 247-250, 2014 (In Chinese).

28. Ouyang BS, Gao J, Che JL, Zhang Y, Li J, Yang HZ, Hu TY, Yang M, Wu YJ and Ji LL: Effect of Electro-acupuncture on tumor necrosis Factor- $\alpha$ and vascular endothelial growth factor in peripheral blood and Joint synovia of patients with rheumatoid arthritis. Chin J Integr Med 17: 505-509, 2011.

29. Chou PC and Chu HY: Clinical efficacy of acupuncture on rheumatoid arthritis and associated mechanisms: A systemic review. Evid Based Complement Alternat Med 2018: 8596918, 2018.

30. He TF, Yang WJ, Zhang SH, Zhang CY, Li LB and Chen YF: Electroacupuncture inhibits inflammation reaction by upregulating vasoactive intestinal peptide in rats with adjuvant-induced arthritis. Evid Based Complement Alternat Med 2011: 1-8, 2011.

31. Zhu J, Chen XY, Li LB, Yu XT, Zhou Y, Yang WJ, Liu Z, Zhao N, Fu C, Zhang SH and Chen YF: Electroacupuncture attenuates collagen-induced arthritis in rats through vasoactive intestinal peptide signalling-dependent re-establishment of the regulatory T cell/T-helper 17 cell balance. Acupunct Med 33: 305-311, 2015.

32. Dong ZQ, Zhu J, Lu DZ, Chen Q and Xu YL: Effect of electroacupuncture in 'Zusanli' and 'Kunlun' acupoints on TLR4 signaling pathway of adjuvant arthritis rats. Am J Ther 25 e314-e319, 2018.

33. Chen L, Wu Q, Yang M, Deng S, Bai L, Chen L and Liang L: Research review of the action mechanism of acupuncture based on cell apoptosis. Shanghai J Acupuncture Moxibustion 35: 1143-1146, 2016 (In Chinese).

34. Liu J, Zhang Y, Sun J, Xu S and Zhang X: Effect of acupuncture on the p53 Protein expression of mice with Alzheimer's disease. Chin J Integrated Traditional Western Med 33: 1367-1371, 2013 (In Chinese)

35. Park JY, Choi H, Baek S, Jang J, Lee A, Jeon S, Kim J and Park HJ: p53 signalling mediates acupuncture-induced neuroprotection in Parkinson's disease. Biochem Biophys Res Commun 460 772-779, 2015.

36. An N, Xu T, Sun Q and Zhang H: Research on effect of electroacupuncture on MDM2 expression in hypoxic-ischemic encephalopathy rat model. Chin Arch Traditional Chin Med 34: 289-292, 2016 (In Chinese).

37. Shi WY, Yan J, Chang XR, Lou BD, Li JX, Huang J, Lin H, Wang $\mathrm{C}$ and Zhang W: Observation of electroacupuncture intervention on cell apoptosis and Bax and Bcl-2 expression in cerebral and myocardial tissues in cerebral ischemia rats based on 'heart-brain correlation' theory. Zhen Ci Yan Jiu 44: 107-112, 2019 (In Chinese)

38. Zhu Y and Zeng Y: Electroacupuncture protected pyramidal cells in hippocampal CA1 region of vascular dementia rats by inhibiting the expression of P53 and Noxa. CNS Neurosci Ther 17: 599-604, 2011.

39. Shalev M: APHIS, FDA, and NIH issue memorandum of understanding on laboratory animal welfare. Lab Anim (NY) 15: 13, 2006.

40. Li P, Xie G, Song S, Huang P, Wu Y, Wang Q, Chang Y, Zhang Y, Zhou A, Liu L, et al: Clinical manifestations and the main evaluation method on adjuvant-induced arthritis model in rats. Chin J Immunol 28: 453-457, 2012 (In Chinese)

41. Ai X, Hou Y, Wang X, Wang X, Liang Y, Zhu Z, Wang P, Zeng Y, Li X, Lai X, et al: Amelioration of dry eye syndrome in $\mathrm{db} / \mathrm{db}$ mice with diabetes mellitus by treatment with Tibetan Medicine Formula Jikan mingmu drops. J Ethnopharmacol 241: 111992, 2019.

42. Hou Y, Wang X, Chen X, Zhang J, Ai X, Liang Y, Yu Y, Zhang Y, Meng X, Kuang T and Hu Y: Establishment and evaluation of a simulated high-altitude hypoxic brain injury model in SD rats. Mol Med Rep 19: 2758-2766, 2019.

43. Livak KJ and Schmittgen TD: Analysis of relative gene expression data using real-time quantitative PCR and the 2(-Delta Delta C(T)) method. Methods 25: 402-408, 2001
44. Wang X, Hou Y, Li Q, Li X, Wang W, Ai X, Kuang T, Chen X, Zhang Y, Zhang J, et al: Rhodiola crenulata attenuates apoptosis and mitochondrial energy metabolism disorder in rats with hypobaric hypoxia-induced brain injury by regulating the HIF-1 $\alpha /$ microRNA 210/ISCU1/2(COX10) signaling pathway. J Ethnopharmacol 241: 111801, 2019.

45. Zhu J, Su CG, Chen YZ, Hao XY and Jiang JZ: Electroacupuncture on ST36 and GB39 acupoints inhibits synovial angiogenesis via downregulating HIF-1 $\alpha$ /VEGF expression in a rat model of adjuvant arthritis. Evid Based Complement Alternat Med 2019: 5741931, 2019.

46. Müller-Ladner U and Pap T: Pathogenesis of RA: More than just immune cells. Z Rheumatol 64: 396-401, 2005 (In German).

47. Bottini N and Firestein GS: Duality of fibroblast-like synoviocytes in RA: Passive responders and imprinted aggressors. Nat Rev Rheumatol 9: 24-33, 2013.

48. Baier A, Meineckel I, Gay S and Pap T: Apoptosis in rheumatoid arthritis. Curr Opin Rheumatol 15: 274-279, 2003.

49. Peng C, Luo L, Hu L, Wu Z, Cai R, Hao F, Hu W and Hong J: Study on the effect of moxibustion in treating rhreumatoid arthritis rats and its mechanism. J Acupuncture Tuina Sci 10: 336-341, 2012 (In Chinese)

50. Zhang C, Cai R and Tang Z: Influences of moxibustion on inflammatory factors and synoviocytes in rats with rheumatoid arthritis. J Beijing Univ Traditional Chin Med 37: 190-194, 2014 (In Chinese).

51. Chen L, Wu QF, Yang MX, et al: Research review of the action mechanism of acupuncture based on cell apoptosis. Shanghai J Acupuncture Moxibustion 35: 1143-1146, 2016 (In Chinese)

52. Gao W, Deng Q, Bai S and Tong L: Establishment and characteristic analysis of fibroblast-like synoviocytes in rats with adjuvant arthritis. Chin Pharmacol Bulletin 12: 1693-1698, 2015.

53. Meng Q, Du X, Wang H, Gu H, Zhan J and Zhou Z: Astragalus polysaccharides inhibits cell growth and pro-inflammatory response in IL-1 $\beta$-stimulated fibroblast-like synoviocytes by enhancement of autophagy via PI3K/AKT/mTOR inhibition. Apoptosis 22: 1138-1146, 2017.

54. Dekkers JS, Schoones JW, Huizinga TW, Toes RE and van der Helm-van Mil AH: Possibilities for preventive treatment in rheumatoid arthritis? Lessons from experimental animal models of arthritis: A systematic literature review and meta-analysis. Ann Rheum Dis 76: 458-467, 2017.

55. Taşçi Bozbas G, Yilmaz M, Paşaoğlu E, Gürer G, Ivgin R and Demirci B: Effect of ozone in Freund's complete adjuvant-induced arthritis. Arch Rheumatol 33: 137-142, 2018.

56. Smolen JS, Aletaha D and McInnes IB: Rheumatoid arthritis. Lancet 388: 2023-2038, 2016.

57. Ren XY, Liu QX and Wang HY: p53 and cell death. Chin J Bioch Mol Biol 34: 588-594, 2018

58. Zhen D, Zhao F and Song H: Progress of polysaccharides regulating p53 signal network. Chin J Cell Biol 39: 1234-1242, 2017.

59. Peng L, Liu J, Xie X, et al: The research progress of p53 regulating the balance of tumor and aging. Chem Life 37: 515-520, 2017 (In Chinese)

60. Zhu J, Chen X, Li L, Zhou Y, Bing X and Chen Y: Experimental study on vasoactive intestinal peptide mediated by electroacupuncture for the treatment of collagen-induced arthritis in rats. Shanghai J Traditional Chin Med 49: 72-76, 2015 (In Chinese).

61. Lassus P, Bertrand C, Zugasti O, Chambon JP, Soussi T, Mathieu-Mahul D and Hibner U: Anti-apoptotic activity of p53 maps to the $\mathrm{COOH}$-terminal domain and is retained in a highly oncogenic natural mutant. Oncogene 18: 4699-4709, 1999.

62. Nakajima T, Aono H, Hasunuma T, Yamamoto K, Shirai T, Hirohata $\mathrm{K}$ and Nishioka K: Apoptosis and functional Fas antigen in rheumatoid arthritis synoviocytes. Arthritis Rheum 38 485-491, 1995.

63. Firestein GS, Yeo M and Zvaifler NJ: Apoptosis in rheumatoid arthritis synovium. J Clin Invest 96: 1631-1638, 1995.

64. Kobayashi T, Okamoto K, Kobata T, Hasunuma $\mathrm{T}$ and Nishioka K: Apomodulation as a novel therapeutic concept for the regulation of apoptosis in rheumatoid synoviocytes. Curr Opin Rheumatol 11: 188-193, 1999.

65. Yao Q, Wang S, Glorioso JC, Evans CH, Robbins PD, Ghivizzani SC and Oligino TJ: Gene transfer of p53 to arthritic joints stimulates synovial apoptosis and inhibits inflammation. Mol Ther 3: 901-910, 2001.

66. Tang B, You X, Zhao L, Zhang T, Zhang L, Zhang X and Tang F: The effect of p53 expression in fibroblast-like synoviocytes on $\mathrm{CD} 4^{+} \mathrm{T}$ lymphocytes in patients with rheumatoid arthritis. Chin J Rheumatol 13: 587-591, 2009 (In Chinese). 
67. Vassilev LT, Vu BT, Graves B, Carvajal D, Podlaski F, Filipovic Z, Kong N, Kammlott U, Lukacs C, Klein C, et al: In vivo activation of the p53 pathway by small-molecule antagonists of MDM2. Science 303: 844-848, 2004.

68. Yang E, Zha J, Jockel J, Boise LH, Thompson CB and Korsmeyer SJ: Bad, a heterodimeric partner for Bcl-XL and Bcl-2, displaces Bax and promotes cell death. Cell 80: 285-291, 1995.

69. Oda E, Ohki R, Murasawa H, Nemoto J, Shibue T, Yamashita T, Tokino T, Taniguchi T and Tanaka N: Noxa, a BH3-only member of the Bcl-2 family and candidate mediator of p53induced apoptosis. Science 288: 1053-1058, 2000.

70. Liu FT, Newland AC and Jia L: Bax conformational change is a crucial step for PUMA-mediated apoptosis in human leukemia. Biochem Biophys Res Commun 310: 956-962, 2003.

71. Seca S, Patrício M, Kirch S, Franconi G, Cabrita AS and Greten HJ: Effectiveness of acupuncture on pain, functional disability, and quality of life in rheumatoid arthritis of the hand: Results of a double-blind randomized clinical trial. J Altern Complement Med 25: 86-97, 2019.
72. Liu Z, Liu Y, Xu H, He L, Chen Y, Fu L, Li N, Lu Y, Su T, Sun J, et al: Effect of electroacupuncture on urinary leakage among women with stress urinary incontinence: A randomized clinical trial. JAMA 317: 2493-2501, 2017.

73. Liu Z, Yan S, Wu J, He L, Li N, Dong G, Fang J, Fu W, Fu L, Sun J, et al: Acupuncture for chronic severe functional constipation: A randomized trial. Ann Intern Med 165: 761-769, 2016.

74. Song JG, Li HH, Cao YF, Lv X, Zhang P, Li YS, Zheng YJ, Li Q, Yin PH, Song SL, et al: Electroacupuncture improves survival in rats with lethal endotoxemia via the autonomic nervous system. Anesthesiology 116: 406-414, 2012.

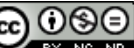

This work is licensed under a Creative Commons Attribution-NonCommercial-NoDerivatives 4.0 International (CC BY-NC-ND 4.0) License. 